\title{
The Influence of Classroom Seating Position on Student Learning Gains in Primary Schools in Kenya
}

\author{
Moses Waithanji Ngware ${ }^{1}$, James Ciera ${ }^{1,2}$, Peter K. Musyoka ${ }^{1}$, Moses Oketch ${ }^{1}$ \\ ${ }^{1}$ Education Research Program, African Population and Health Research Center, Nairobi, Kenya \\ ${ }^{2}$ African Institute for Development Policy, Nairobi, Kenya \\ Email: mngware@aphrc.org,jmciera@yahoo.com,petmusyoka@yahoo.com, moketch@aphrc.org
}

Received September $18^{\text {th }}, 2013$; revised October $18^{\text {th }}, 2013$; accepted October $25^{\text {th }}, 2013$

Copyright (C) 2013 Moses Waithanji Ngware et al. This is an open access article distributed under the Creative Commons Attribution License, which permits unrestricted use, distribution, and reproduction in any medium, provided the original work is properly cited.

\begin{abstract}
This paper examines the contribution of classroom students' seating positions to learning gains. Data were gathered from a sample of 1907 grade six students who sat for the same seat twice over an interval of about 10 months. They were drawn from a random selection of 72 low and high performing primary schools. Results of a multi-level regression show that seating in the front row in a classroom led to higher learning gains of between 5 percent and 27 percent compared to seating in other rows that are farther away from the chalkboard. The policy implication to education is that student's seating position can be manipulated in a way that it optimizes learning gains for slow learners.
\end{abstract}

Keywords: Classroom; Assessment; Learning; Seat; Teaching

\section{Introduction}

Teaching is a profession that requires specialized skills and knowledge to impact significantly on student learning. One factor associated with improved achievement among learners is the position at which they sit in a classroom. For example, several studies (Levine, O’Neal, Garwood, \& McDonald, 1980; Marx, Fuhrer, \& Hartig, 2006; Siang, 1991; Tagliacollo, Volpato, \& Pereira Jr., 2010) have shown that those pupils who sit in the front tend to be more active and have higher achievement scores. These learners, therefore, have better interaction with teachers and gain more from each lesson than those who sit at the back of the classroom and are somewhat "hidden" from the teacher (Marx et al., 2006). However, as the debate on quality of education and opportunity to learn is becoming the primary focus for many Sub-Sahara Africa (SSA) countries that have made significant improvement on access to schooling, there is the need to revisit this classroom seating position advantage. Most studies on seat position in the classroom and how it influences learner achievement are to be found outside Africa. But in spite of the limited literature on seat position in the classroom in SSA, many countries have initiated Universal Primary Education (UPE) programs that have led to improved access to schooling, and in some cases to overcrowded classrooms. In an overcrowded classroom, seat position is critical as it determines access to the learning resources and opportunities inside the classroom.

Available literature shows that students who sit near the chalkboard have better school performance compared to those who sit far away from the chalkboard (Benedict \& Hoag, 2004; Perkins \& Wieman, 2005). Teachers' instructional space is near the chalkboard and hence those seated in the front are more likely to interact with their teachers. Seating at the back of the class has been associated with problem behavior as well as low grades (Perkins \& Wieman, 2005). Earlier studies show that teachers tend to direct more questions to students seated in the front rows of the classroom (Juhary, 2012; Moore \& Glynn, 1984). Students seated at the back interact more with each other, in a disruptive way, thus minimizing their opportunity to learn (Granstrom, 1996).

However, other studies have found no detrimental effects of sitting at the back on learning achievement (see for example Kalinowski, \& Taper, 2007). According to Taglioacollo et al. (2010), achievement has led teachers to move students closer to the chalkboard with a view toward raising their grades, but that outcome may not always be realized. Taglioacollo et al., (2010) posit that motivation to learn is the mediating factor between seat position and student academic achievement, and hence there exists no direct effect of seat position on student academic performance. Taglioacollo et al. concluded that students' motivation to learn is the main determinant of seat position. This may not always be true, for instance, some teachers may assign students to seats regardless of student preference.

\section{The Milieu}

In Kenya, the Free Primary Education (FPE) program was introduced in 2003 and brought over one million children into the public school system (Government of Kenya, 2005). Consequently, class sizes of as many as 80 students exist in public primary schools (Ngware, Oketch, \& Ezeh, 2011). With a large class size, seating position becomes an important determinant of opportunity to learn, and it may influence student achievement (Tagliacollo et al., 2010). At the same time, public expectations on teachers to produce better grades on examinations remain high despite large class sizes. 
$\mathrm{KCPE}$ is a national standardized test that all students completing grade eight take. Their scores on that test are the major determinant of the high school into which they are ultimately enrolled. High scoring students gain admission to competitive high schools. This raise their chances of scoring well on the parallel standardized high school exams and, therefore, make it more likely that they will earn one of the comparatively few places available within the public and private university system. $\mathrm{KCPE}$ is, therefore, a high-stake exam. Within the context of FPE, there exist schools in the same neighborhood that persistently perform well and others that persistently perform poorly in standardized national examinations. Examining the students' seating position will improve our understanding of what happens in the classroom that may explain some of the differences in performance among pupils and schools. Teacher-classroom interactions that aid student learning are often complex processes that hinge on interpersonal and pedagogical awareness. The teacher's classroom management strategies and interactions with students at the classroom level can determine how much is learned (Morrison, Bachman, \& Connor, 2005).

In this paper, we examine the effects of seating position on increases in student achievement at the classroom level. The research question to be answered in this paper is "Does student classroom seating positions explain learning gains?" By answering this question, the paper contributes to the debate on classroom environment and learning achievement. This paper also contributes to filling the gap that exists in sub Saharan Africa (SSA) on research evidence of what is happening in the classroom.

\section{Methods}

\section{Sampling}

For the purpose of selecting the highest and lowest performing districts and schools, the Kenya Certificate of Primary Examination (KCPE) results of the last four available years (20022005) were used to rank districts and schools. School performance in national examinations (a proxy indicator for student achievement) in Kenya varies by district. Some districts persistently score high, while other districts are repeatedly low performers. Based on the distribution of school mean scores in a district, schools were categorized as low performing and high performing.

Six districts were randomly selected, two from those that were consistently ranked in the bottom $10 \%$ in KCPE examinations over the past 4 years, two from those that were consistently ranked in the middle $20 \%$, and another two from those that were consistently ranked in the top $10 \%$ over the same period. Seventy-two schools, 12 in each of the six districts, were randomly selected for the study-six that consistently rank in the bottom $20 \%$ and six that consistently rank in the top $20 \%$ in each of the districts. Data for this paper were collected from 72 head teachers, 72 math teachers, and 1907 grade six students who sat for the same math test, administered by the study team, in rounds one and two.

To collect data, several instruments and techniques were used. Three survey instruments and two assessment tools were developed and pre-tested to improve the validity and reliability. The three survey instruments include a head teacher questionnaire that solicited information on school management, staffing, enrolment, and parental participation in school affairs among others; a teacher questionnaire that solicited information on demographics, qualification and training, discipline, and syllabus coverage; a learner questionnaire that collected information on social economic backgrounds of the grade six learners and their perceptions of the school environment. This questionnaire was administered to grade six students in the selected schools. The assessment tools included a grade six mathematics teacher test and a learner mathematics test for grade six students. The return rates of the research instruments from the participants were quite high; $100 \%$ for the head teachers, $97.6 \%$ for teachers, and $99.8 \%$ for the students.

\section{Variable Descriptions}

In this paper, the dependent variable is gain score while the main explanatory variable is student seating position. These variables are defined as follows:

Gain score: The difference between pupil score in test (round) one and two. Test one and two had the same test items but were administered ten months apart. For the purposes of fitting a regression model, Item Response Theory (IRT) scale procedures were used to compute a gain score from the raw scores for each student. We then computed gain scores from the IRT scale scores by simply subtracting each student's IRT mathematics scale score in test one from their score in test two. This gave us the IRT scale score points the students gained between rounds one and two.

Seating position: In all schools, students sat in desks of three or four. A few schools had lockers placed together in $2 \mathrm{~s}, 3 \mathrm{~s}$, or $4 \mathrm{~s}$ forming a set/group that fits in a column width. Seating position was the classroom physical seat position occupied by the student relative to the front of the classroom. The front of the classroom was taken to be the side with the chalkboard. Student seating position was allocated a three-digit number- $\mathrm{i}, \mathrm{j}$ and $\mathrm{k}$ for purposes of mapping the seat position of the student in the classroom. For example, ijk meant ith row in the jth column, student $\mathrm{k}$. Rows were serialized from the front of the classroom. The three digit number was recorded in the student's assessment tool.

\section{Conceptualization}

The paper uses a value-added approach to investigate the influence of quality of teaching and seating position on learning gains. A value-added approach was chosen for two main features. First, the dependent variable is designed to measure the amount of change that occurs in learning (i.e. gain score) during the period when students are in classroom. Second, measures of change were adjusted for differences across classrooms in the student's prior achievement (entry behavior), students' socioeconomic background, and other school factors (Harris \& Sass, 2007; McCaffrey et al., 2004; Rowan, Correnti, \& Miller, 2002). According to Rowan et al. (2002), the aim of a valueadded model is to approximate size of variance changes in student learning achievement within classrooms after controlling for the effects of other variables.

From this brief background, we conceptualize the effects of seat position to be independent of that of other factors including student characteristics, teacher factors, teaching quality and school/classroom context. IRT-scale gain score is the dependent variable, and IRT round one scores adjusts for initial academic performance that can probably be the source of changes in 
learning achievement. We carry out a two-level analysis (student and school) that assumes classrooms and schools are the same (one sixth grade teacher per school). Therefore, we use cluster correction in STATA to correct standard errors in the regression analyses.

We estimate a multi-level linear regression following the value-addition models derived from a basic educational production function (EPF). In theory, student learning achievement is determined by an EPF:

$$
A=f(H, I, S, \alpha)
$$

where achievement $\mathrm{A}$ is a product of home or social economic background $(\mathrm{H})$, individual characteristics (I), school resource inputs (S), and an efficiency parameter measuring capacity utilization in the school $(\alpha)$ (Marshall, 2009). This general EPF does not specify effects levels of the determinants of learning achievement. Showing the effects levels is relevant to policy since it enhances the understanding of the learning achievement dynamics. According to Glewwe (2002), if the independent variables do not change much over time, the analysis of levels will return similar results to that of a general EPF. Three models are estimated: 1) the overall model that includes all schools; 2) one model for the top performing schools; and, 3) one model for the bottom performing schools.

The multivariate model assumes that all pupils have the same or varying number of repeated IRT measurements taken at identical points in time (Verbeke, \& Molenberghs, 2000). In the analysis, we consider the repeated IRT measurements for all the students and schools computed from the same math test administered in rounds one and two, over an interval of ten months. Let yij1 and yij2 be the IRT scores for round one and two for the $\mathrm{jth}$ pupil in the ith school where $\mathrm{j}=1,2, \ldots$ ni and $\mathrm{i}=1$, $2, \ldots \mathrm{N}$. The two IRT scores can be grouped together in a vector $\mathbf{y}_{i j}=\left[y_{i j 1}, y_{i j 2}\right]$. The pupil's scores $\mathbf{y}_{i j}$ in the $i^{\text {th }}$ school can be clustered into a vector $\mathbf{Y}_{i}=\left[\mathbf{y}_{i 1}, \mathbf{y}_{i 2}, \cdots, \mathbf{y}_{i n_{i}}\right] \mathbf{i}=1$, $2, \ldots \mathrm{N}$. The general multivariate model assumes that the repeated measurements in $\mathbf{Y}_{i}$ satisfy a regression model given by:

$$
\mathbf{Y}_{i}=\mathbf{X}_{i} \boldsymbol{\beta}+\boldsymbol{\varepsilon}_{i}, i=1,2, \ldots N
$$

where $\boldsymbol{\varepsilon}_{i}$ is a vector of error components and $\boldsymbol{\varepsilon}_{i} \sim N(0, \Sigma)$. The response vector for the $i^{\text {th }}$ pupil $\mathbf{Y}_{i}$ has a multivariate normal density $\mathbf{Y}_{i} \sim N\left(\mathbf{X}_{i} \boldsymbol{\beta}, \Sigma\right)$, where $\boldsymbol{\beta}$ is a vector of fixed effects and $\sum$ is the covariance matrix. Since the study has two time points (rounds one and two), we adopt an unstructured covariance matrix for the covariance structure $\sum$. The unstructured covariance matrix offers the most generalized structure that does not assume any prior knowledge of the relationship between the variables of interest.

\section{Results and Discussion}

\section{Descriptive Statistics}

The mean score for the top performing schools was 0.645 and the bottom performing schools was 0.492 . Overall, the mean gain score for all schools was 0.582 . On average, the top schools gained more by 0.153 IRT gain scores, equivalent to a gain of $31 \%$. The IRT scores were distributed normally with the highest peak at the mean. The gain score for the top schools ranged between -2.1 to 4.0 while the range for the bottom school was -2.1 to 2.8 , an indication that top schools had higher gain scores compared to the bottom schools.

Table 1 shows the mean, number of students, percentage of students in each row, and the p-values (significance measures) of a t-test that compares the gain score mean between row one and each of the subsequent seating rows. Rows one and two were at the front of the class, rows three and four were the middle of the class and rows five and six were at the back of the class. On average, each of the first three class rows contained about $18 \%$ of the pupils and the mean gain score varied between 0.524 and 0.687 . It is evident that pupils who sat in row one had the highest gain score. With an exception of row four in both the overall sample and bottom schools, the rest of the rows had significantly less mean gain score compared to row one.

Appendix A shows the mean gain score based on student, teacher, and other school characteristics. On student characteristics, we computed the means depending on whether a student had math tuition, the student's gender and age, the student's household wealth index, number of times a student repeated grade(s), student's frequency in speaking English outside school, and desk-group composition (girls, boys or mixed). On teacher and school characteristics, we considered school rank, frequency of the head teacher supervision, teacher's highest training level, gender, and teacher's preparedness to teach.

From the descriptive results, it is evident that having math tuition is associated with better gain score. Similarly, pupils from the poor background significantly perform poorly relative to those from wealthy families. Failure to speak English outside school and having repeated a grade are related to lower gain scores. However, student sex does not help improve the gain score since the mean scores for both boys and girls are nearly the same. For school characteristics, top schools performed better than bottom schools as expected, while the head teachers' supervision helped students achieve a higher gain. Desk-group gender composition, teachers' gender, training and preparedness to teach were insignificantly correlated with students' performance in math. Descriptive results suggest that students taught by degree holders scored lower; however, these findings may be a result of small sample size among teachers with degree certificates, who represented $2 \%$ of the total number of teachers in the sample.

\section{Multi-Level Models}

To investigate the effects of seating position on pupils' gain scores, we fitted a multi-level linear regression model while controlling the clustering observed among students that belong to the same class. From the analysis in Descriptive Statistics Section, it was observed that top and bottom performing schools scored differently; hence, we modeled the data for all the sample schools, and then modeled data by school category (top and bottom schools) separately. In each category (top, bottom, and all schools combined), we fitted two multi-level models. The first one is univariate while the second model is a multiple linear regression. The first model fit the gain score against our main explanatory variable - seating position. In the second model we fitted the gain score against the main explanatory variable while adjusting for the related student, teacher, and school characteristics described in the literature as influencing student achievement (Baumert et al., 2010; Georges, Borman, \& Lee, 2010; Goldschmidt \& Phelps, 2010 ). The regression results are as shown in the Appendixes B and $\mathbf{C}$. 
Table 1.

Mean IRT score gain based on seating position.

\begin{tabular}{ccccc}
\hline Seating row & Mean IRT gain score $(\mathbf{s e})$ & $\boldsymbol{N}$ & $\boldsymbol{\%}$ & $\boldsymbol{t}_{\text {-test }} \boldsymbol{p}$-value \\
\hline All schools & & & & \\
row 1 & $0.687(0.035)$ & 434 & 18.0 & - \\
row 2 & $0.576(0.035)$ & 450 & 18.6 & 0.016 \\
row 3 & $0.528(0.033)$ & 438 & 18.1 & 0.001 \\
row 4 & $0.606(0.035)$ & 376 & 15.6 & 0.051 \\
row 5 & $0.524(0.044)$ & 315 & 13.0 & 0.002 \\
row 6+ & $0.556(0.038)$ & 403 & 16.7 & 0.005 \\
Top schools & & & & \\
row 1 & $0.707(0.047)$ & 236 & 17.14 & - \\
row 2 & $0.691(0.054)$ & 247 & 17.94 & 0.017 \\
row 3 & $0.496(0.045)$ & 251 & 18.23 & 0.001 \\
row 4 & $0.715(0.045)$ & 227 & 16.49 & 0.040 \\
row 5 & $0.603(0.055)$ & 195 & 14.16 & 0.002 \\
row 6+ & $0.667(0.053)$ & 221 & 16.05 & 0.007 \\
Bottom schools & & & & \\
row 1 & $0.663(0.052)$ & 198 & 19.1 & - \\
row 2 & $0.444(0.050)$ & 203 & 19.5 & 0.097 \\
row 3 & $0.576(0.049)$ & 187 & 18.0 & 0.014 \\
row 4 & $0.424(0.050)$ & 149 & 14.3 & 0.178 \\
row 5 & $0.381(0.070)$ & 120 & 11.6 & 0.022 \\
row 6+ & $0.398(0.048)$ & 182 & 17.5 & 0.051 \\
\hline
\end{tabular}

Note: *using row 1 as the comparison category.

To investigate the effect of the seating position on students' gain score, we modeled the variable seat position alone, and then fitted other models in which we controlled for individual and school characteristics. The results show that students seated in the first row perform better in comparison to students seated in any other row. When we control for pupil and teacher characteristics, students seated in the first row still had better performance net of students' academic ability. This is an indication that seating in a front row is associated with higher math scores. Modeling the two school categories separately helped us gain a deeper understanding of the interaction of seat position and school category. For example, descriptive analysis shows (see Table 1) that in top schools, students seated in row one had significantly higher mean scores than those seated in the other rows. After controlling for other characteristics in the top school model (see Appendix C), we find that seating in the second row had a lesser effects on learning gains when compared to seating in the first row. Further, seating in row three significantly reduced the score gain. Seating in the other rows led to a reduction in gain scores, though not significant (at $\alpha=$ 0.05). In bottom performing schools (Appendix C), the effect of seating position is more pronounced. Univariate analysis showed that with reference to the first row, seating in any other row (except in row 4) significantly reduced the score gain. After controlling for other student, teacher, and school characteristics, the effect of seating position remains significant.

From these findings, we can argue that either higher achievers sit in the front row, and/or seating in the front row improves learning gains. Since we controlled for initial academic ability (test one scores), we conclude the latter. Kaya and Burgess (2007), Martin (2002), and Thomas (2003), have examined classroom seating arrangements and pupil's in-class nonacademic behavior. They found that seating position is important because it has the potential to prevent the problem behaviors that decrease student attention and probably this can diminish opportunities to learn. Wannarka and Ruhl (2008) has suggested that such problem behavior influences achievement. Students seated in the front row have an advantage over students in other rows because of their closeness to the teacher, and they are engaged more during instruction. Such active engagement leads to more learning opportunities and higher learning gains. This line of argument has been supported by Higgins et al. (2005) who observed that advanced involvement between teacher and students occur across the front and down the middle of the classroom. This implies that students in the first row get more attention of the teacher during classroom instructions which led to more learning gains. Our findings contradict the results of Kalinowski and Taper (2007) who found no detrimental effect of sitting at the back on learning achievement among college students in Montana. However we confirm the findings of Benedict and Hoag (2004), and Perkins and Wieman (2005) in Bowling Green State University and Colorado respectively; they found that seating in front has an academic advantage.

We tested the relative importance of the seating position on learning gains. We used the likelihood ratio test based on the school sample dataset as well as the separate data for top and bottom schools. For the entire school sample, seating position is highly significant (chi-square $=19.75, p=0.011$ ). In top schools, seating position is significant (chi-square $=32.24, p=$ $0.003)$. In the bottom schools seating position is not significant.

Other pupil-level variables in the model included score for test one, desk-group score for test one, mathematics tuition, pupil's age, gender, household wealth index, frequency of grade repetition, and the frequency with which the pupil spoke English outside of school. Desk-group composition was used to measure peer influence within the class. It referred to the gender composition of pupils who sat at the same desk. Seat group composition did not have any significant effect on score gain in the top schools model. However, in the model for bottom schools, boys only desk-groups performed marginally better $(15 \%)$ than girls only desk-groups. In top performing schools, an increase in student teacher ratio (PTR) significantly lowers the score gain by $1 \%$.

Accounting for inter-class variability is an important aspect when modeling multi-level data. Based on a scale of 0 to 1 , the estimated variability between school mean scores was 0.135 while the variability among students in the same school was 0.589 . This indicates that the variability among students in the same school is almost five times higher than the variability between school mean scores. This suggests that variability is pronounced more within a school than between schools. However, when we model the top and bottom performing schools separately, the school-mean variability reduces dramatically, an indication that the observed variability between schools is due primarily to the school category (i.e. top or bottom performing schools). These findings suggest that each of the top and bottom school categories have homogenous school characteristics.

\section{Conclusion}

This study uses survey and assessment data from urban and rural Kenyan primary schools to examine the effects of student 
seating position on learning achievement gains. The study uses gain score as the outcome variable to measure the amount of learning that took place within an interval of 10 months, with the same math test being administered twice. This rich data and our analyses made it possible to generate scientific evidence that we use to fill several existing gaps in the literature. For example, extant literature on learning achievement in Kenya has not used score gains as an outcome measure, and instead it relies on test and national examination scores; there is no literature on Kenya that links seat position to learning gains.

The consideration of the student's seat position relative to the student's academic ability in the Kenyan primary school classroom deserves more attention. Our analysis shows that seating in the front row has a positive and significant effect on learning achievement. Our results corroborate what other studies outside Kenya have found, though not using gain score.

The linkages between seating position and learner achievement have important implications for education policy and classroom practices in Kenya. Teachers can change classroom seating positions in a way that optimizes learning achievement for every learner, since the seat position has the potential to improve achievement gains. In particular, low performing learners can improve their grades by seating at the front rows especially in large class sizes. However, the teacher would have to monitor the progress of those seated away from the front rows, even if such students are high performers. That is, the teachers should pay attention to the different seating rows for the benefit of all students. Teacher preparation programs, both in-service and pre-service, and teacher employers need to emphasize more on classroom environment. This paper shows how our main explanatory variable predicts learning gains in schools that are different academically. Although managing classroom physical environments has the potential to address learning differentials, different seating positions and arrangements should be tested for their efficiency in instructional delivery and effectiveness in improving learning outcomes among learners with different academic ability.

\section{Acknowledgements}

We acknowledge the important contribution of the African Population and Health Research Center (APHRC) staff who participated at various stages of the development of this paper including data collection and processing as well as giving valuable comments during the internal review process. We are also grateful to our partners including the Ministry of Education for providing us with introductory letters to the District Education Officers and school head teachers. Funding for this study was provided by Google.org through the Education Research Program at APHRC. We are grateful to The William and Flora Hewlett Foundation for their continued support. Finally, we are grateful to the school principals, teachers, and learners who participated in this study. The views presented in this paper are only those of the authors and not necessarily shared by those mentioned.

\section{REFERENCES}

Benedict, M. E., \& Hoag, J. (2004). Seating location in large lectures: Are seating preferences or location related to course performance? Journal of Economic Education, 35, 215-231. http://dx.doi.org/10.3200/JECE.35.3.215-231
Baumert, J., Kunter, M., Blum, W., Brunner, M., Voss, T., Jordan, A., et al. (2010). Teachers' mathematical knowledge, cognitive activation in the classroom, and student progress. American Educational Research Journal, 47, 371-406. http://aerj.aera.net http://dx.doi.org/10.3102/0002831209345157

Georges, A., Borman, K. M., \& Lee, R. S. (2010). Mathematics reform and teacher quality in elementary grades: Assessments, teacher licensure, and certification. Educational Policy Analysis Archives, 18, 1-36. http://epaa.asu.edu/epaa/757

Glewwe, P. (2002). Schools and skills in developing countries: Education policies and socioeconomic outcomes. Journal of Economic Literature, 40, 436-482.

http://dx.doi.org/10.1257/002205102320161258

Goldschmidt, P., \& Phelps, G. (2010). Does teacher professional development affect content and pedagogical knowledge: How much and for how long? Economics of Education Review, 29, 432-439. http://dx.doi.org/10.1016/j.econedurev.2009.10.002

Government of Kenya (2005). Education statistical booklet 1999-2004. Nairobi: Ministry of Education Science and Technology.

Granstrom, K. (1996). Private communication between students in a classroom in relation to different classroom features. Educational Psychology, 16, 349-364. http://dx.doi.org/10.1080/0144341960160401

Harris, D. N., \& Sass, T. R. (2007). Teacher training, teacher quality and student achievement. CALDER Working Paper No. 3. http://www.caldercenter.org/PDF/1001059_Teacher_Training.pdf

Higgins, S., Hall, E., Wall, K., Woolner, P., \& McCaughey, C. (2005). The impact of school environments: A literature review. Callaghan, NSW: University of Newcastle. http://www.cfbt.com/PDF/91085.pdf

Juhary, J. (2012). An assigned seating arrangement based on students' performance: A critical review. Journal of Education and Practice, 3. (Online)

http://www.iiste.org/Journals/index.php/JEP/article/view/3414/3441

Kalinowski, S., \& Taper, M. L. (2007). The effect of seat location on exam grades and student perceptions in an introductory biology class. Journal of College Science Teaching, 36, 54-57.

Kaya, N., \& Burgess, B. (2007). Territoriality seat preferences in different types of classroom arrangements. Environment and Behaviour, 39, 859-879. http://eab.sagepub.com http://dx.doi.org/10.1177/0013916506298798

Levine, D. W., O’Neal, E. C., Garwood, S. G., \& McDonald, P. J. (1980). Classroom ecology: The effects of seating position on grades and participation. Personality and Social Psychology Bulletin, 6, 409-412. http://psp.sagepub.com/content/6/3/409.abstract

Marshall, J. H. (2009). School quality and learning gains in rural Guatemala. Economics of Education Review, 28, 207-216. http://dx.doi.org/10.1016/j.econedurev.2007.10.009

Martin, S. H. (2002). The classroom environment and its effect on the practice of teachers. Journal of Environmental Psychology, 22, 139156. http://dx.doi.org/10.1006/jevp.2001.0239

Marx, A., Fuhrer, U., \& Hartig, T. (2006). Effects of classroom seating arrangements on children's question-asking. Learning Environment Research, 2, 249-263. http://dx.doi.org/10.1023/A:1009901922191

McCaffrey, D. F., Lockwood, J. R., Koretz, D., Louis, T. A., \& Hamilton, L. (2004). Models for value-added modeling of teacher effects. Journal of Educational and Behavioral Statistics, 29, 67-101. http://dx.doi.org/10.3102/10769986029001067

Morrison, F. J., Bachman, H. J., \& Connor, C. M. (2005). Improving literacy in America: Guidelines from research. New Haven, CT: Yale University Press.

Moore, D. W., \& Glynn, T. (1984). Variations in question rate as a function of position in the classroom. Educational Psychology, 4, 233-248. http://dx.doi.org/10.1080/0144341840040304

Ngware, M. W., Oketch, M., \& Ezeh, A. C. (2011). Quality of primary education inputs in urban schools: Evidence from Nairobi. Education and Urban Society, 43, 91-116. http://dx.doi.org/10.1177/0013124510379131

Perkins, K. K., \& Wieman, C. (2005). The surprising impact of seat location on student performance. The Physics Teacher, 43, 30-33. http://dx.doi.org/10.1119/1.1845987 
Rowan, B., Correnti, R., \& Miller, R. J. (2002). What large-scale, survey research tells us about teacher effects on student achievement: Insights from the prospects study of elementary schools. Consortium for Policy Research in Education, Research Report Series RR-051.

http://www.americancivil.literacy.org/sites/default/files/researchrepo rt/791_rr51.pdf

Siang, T. K. (1991). The effects of seat location on students' learning behaviour in the classroom. Singapore Journal of Education, 11, 7175. http://dx.doi.org/10.1080/02188799108547675

Tagliacollo, V. A., Volpato, G. L., \& Pereira Jr., A. (2010). Association of student position in classroom and school performance. Educa- tional Research, 1, 198-201.

http://interesjournal.org/ER/Abstracts/2010\%20abstract/July/Tagliacoll o\%20et $\% 20$ al.htm

Thomas, B. (2003). Take my chair (please). Chronicle of Higher Education, 49, 36-38.

Verbeke, G., \& Molenberghs, G. (2000). Linear mixed models for longitudinal data. New York: Springer,

Wannarka, R., \& Ruhl, K. (2008). Seating arrangements that promote positive academic and behavioural outcomes: A review of empirical research. Support for Learning, 23, 89-93.

http://dx.doi.org/10.1111/j.1467-9604.2008.00375.x 
Appendix A: Mean IRT score gain based on pupil, teacher, and school characteristics.

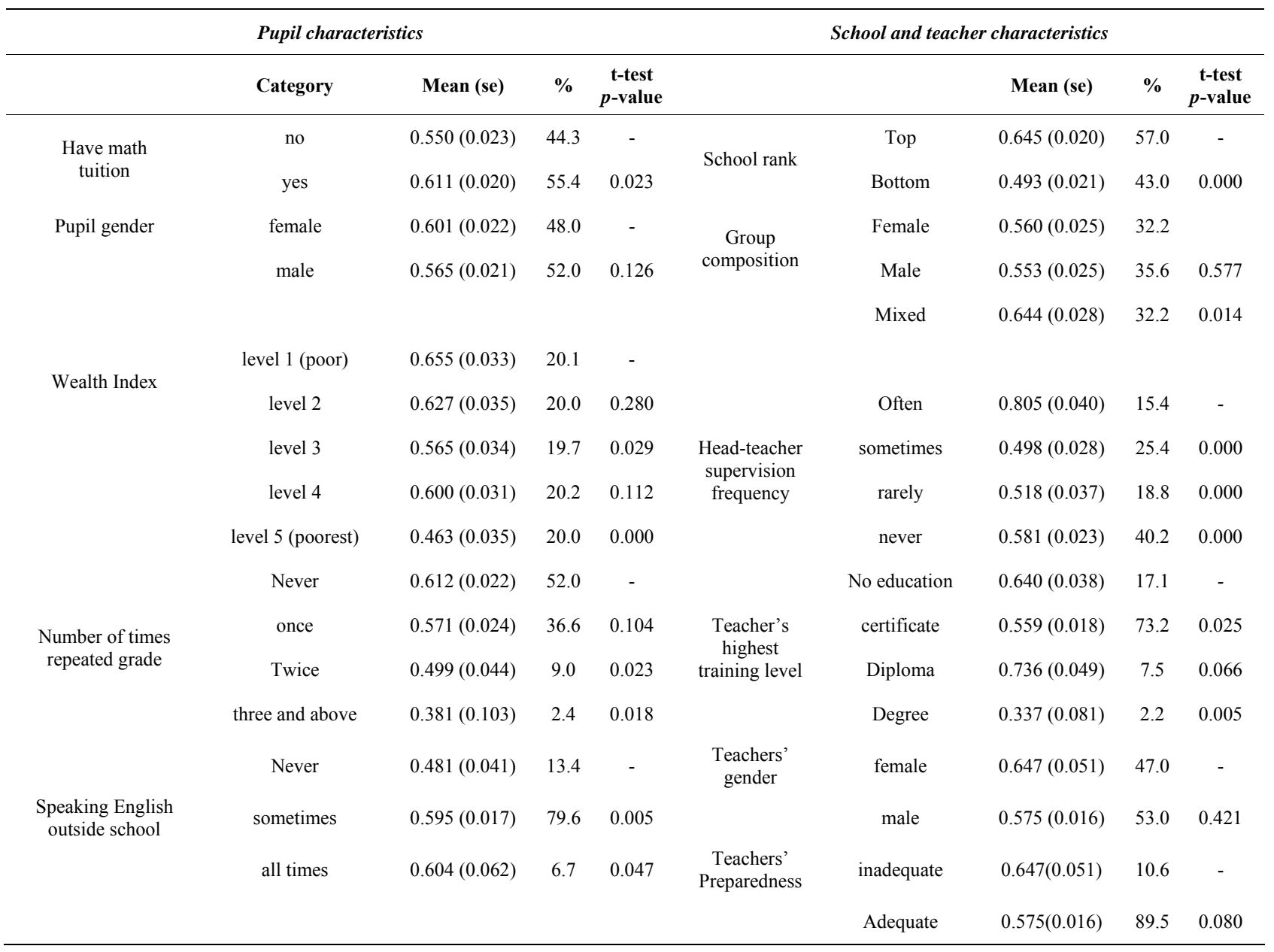

Appendix B: Univariate linear regression model based on all schools, top and bottom performance schools.

\begin{tabular}{|c|c|c|c|c|c|c|c|}
\hline \multirow[b]{2}{*}{ Variable } & \multirow[b]{2}{*}{ Category } & \multicolumn{2}{|c|}{ All schools } & \multicolumn{2}{|c|}{ Top schools } & \multicolumn{2}{|c|}{ Bottom schools } \\
\hline & & Coefficient & p-value & Coefficient & p-value & Coefficient & p-value \\
\hline Intercept & & 0.68 & 0.000 & 0.70 & 0.000 & 0.66 & 0.000 \\
\hline \multicolumn{8}{|l|}{ Pupil characteristics } \\
\hline \multirow[t]{5}{*}{ Seating Row (ref: row 1) } & row 2 & -0.11 & 0.016 & -0.03 & 0.612 & -0.21 & 0.001 \\
\hline & row 3 & -0.15 & 0.001 & -0.21 & 0.001 & -0.08 & 0.275 \\
\hline & row 4 & -0.09 & 0.076 & 0.00 & 0.949 & -0.24 & 0.001 \\
\hline & row 5 & -0.17 & 0.001 & -0.14 & 0.039 & -0.26 & 0.001 \\
\hline & row 6 and above & -0.18 & 0.001 & -0.16 & 0.025 & -0.25 & 0.001 \\
\hline \multicolumn{8}{|l|}{ Class and pupil variances } \\
\hline class variability & & 0.212 & & 0.257 & & 0.075 & \\
\hline pupil variability & & 0.617 & & 0.627 & & 0.595 & \\
\hline inter-class correlation & & 0.104 & & 0.144 & & 0.016 & \\
\hline Log likelihood & & -1809.48 & & -1097.10 & & -714.69 & \\
\hline
\end{tabular}


M. W. NGWARE ET AL.

Appendix C: Multiple linear regression model based on: all schools, top and bottom performance schools.

\begin{tabular}{|c|c|c|c|c|c|c|c|}
\hline \multirow[b]{2}{*}{ Variable } & \multirow[b]{2}{*}{ Category } & \multicolumn{2}{|c|}{ All schools } & \multicolumn{2}{|c|}{ Top schools } & \multicolumn{2}{|c|}{ Bottom schools } \\
\hline & & Coefficient & p-value & Coefficient & p-value & Coefficient & p-value \\
\hline Intercept & & 0.58 & 0.148 & 1.20 & 0.023 & 2.21 & 0.112 \\
\hline \multicolumn{8}{|l|}{ Pupil characteristics } \\
\hline \multirow[t]{5}{*}{ Seating Row (ref: row 1) } & row 2 & -0.11 & 0.016 & 0.01 & 0.881 & -0.19 & 0.003 \\
\hline & row 3 & -0.15 & 0.001 & -0.17 & 0.007 & -0.05 & 0.428 \\
\hline & row 4 & -0.10 & 0.040 & 0.01 & 0.842 & -0.24 & 0.001 \\
\hline & row 5 & -0.18 & 0.000 & -0.11 & 0.095 & -0.27 & 0.001 \\
\hline & row $6+$ & -0.17 & 0.001 & -0.09 & 0.202 & -0.25 & 0.002 \\
\hline IRT score_1 & & -0.27 & 0.000 & -0.21 & 0.000 & -0.36 & 0.000 \\
\hline Group score for test 1 & & 0.00 & 0.142 & 0.00 & 0.652 & 0.01 & 0.002 \\
\hline Pupil gender (ref: female) & male & 0.01 & 0.771 & 0.02 & 0.689 & 0.01 & 0.878 \\
\hline \multirow[t]{4}{*}{ Wealth Index (pupil) (ref: level 1) } & level 2 (poor) & 0.04 & 0.376 & 0.06 & 0.277 & 0.04 & 0.667 \\
\hline & level 3 & 0.03 & 0.557 & 0.00 & 0.970 & 0.08 & 0.354 \\
\hline & level 4 & 0.05 & 0.310 & 0.06 & 0.395 & 0.08 & 0.354 \\
\hline & level 5 (poorest) & 0.02 & 0.667 & 0.09 & 0.224 & 0.03 & 0.741 \\
\hline \multirow[t]{4}{*}{ No of times repeated grade (ref: Never) } & once & -0.05 & 0.146 & -0.05 & 0.306 & -0.05 & 0.242 \\
\hline & twice & -0.11 & 0.045 & -0.15 & 0.064 & -0.08 & 0.321 \\
\hline & three and above & -0.25 & 0.020 & -0.19 & 0.284 & -0.29 & 0.024 \\
\hline & missing & 0.43 & 0.475 & - & & - & \\
\hline \multirow[t]{2}{*}{ Speaking English outside school (ref: Never) } & sometimes & 0.11 & 0.010 & 0.29 & 0.002 & 0.04 & 0.451 \\
\hline & all times & 0.12 & 0.079 & 0.30 & 0.292 & -0.15 & 0.164 \\
\hline \multicolumn{8}{|l|}{ Classroom and school variables } \\
\hline \multirow[t]{2}{*}{ Group composition (ref: female) } & male & 0.09 & 0.085 & 0.05 & 0.460 & 0.15 & 0.056 \\
\hline & mixed & 0.07 & 0.084 & 0.10 & 0.066 & 0.06 & 0.381 \\
\hline Pupils teachers ratio & & -0.01 & 0.005 & -0.01 & 0.000 & -0.01 & 0.142 \\
\hline Class size & & 0.00 & 0.541 & 0.00 & 0.577 & 0.00 & 0.505 \\
\hline School rank (ref: Top 20\% in district) & bottom & -0.18 & 0.004 & - & & - & \\
\hline \multicolumn{8}{|l|}{ Class and pupil variances } \\
\hline class variability & & 0.135 & & 0.075 & & 0.000 & \\
\hline pupil variability & & 0.589 & & 0.598 & & 0.546 & \\
\hline inter-class correlation & & 0.050 & & 0.016 & & 0.000 & \\
\hline Log likelihood & & -1693.7 & & -1019.43 & & -607.13 & \\
\hline
\end{tabular}

